\title{
Figural after-effects and field dependence: Another ground for scepticism
}

PETER C. DODWELL, Queen's University at Kingston, Ont., Canada, and Center for Advanced Study in the Behavioral Sciences, Stanford, Calif. 94305

Recently Pressey \& Koffman (1968) failed to corroborate Immergluck's finding of a relationship between visual figural aftereffects (FAEs) and field-dependency (Immergluck, 1966). This has generated a controversy which hinges largely on methodological issues (Immergluck, 1968; Pressey, 1968), but which misses perhaps the main issue, i.e., the extent to which one can be certain that either the FAEs or field-dependency findings are not pseudoeffects generated by induced set or expectations. The point is probably a substantial one, since the FAE literature is full of conflicting reports, and recently evidence has been accumulating that so-called FAEs (both visual and kinesthetic) may in some cases simply be reports which are biased by the E's instructions (Gaze \& Dodwell, 1965; Story, 1959; Wertheimer \& Sheets, 1968; Willems, 1967). It has recently been shown (Dodwell \& Gendreau, in press) that differences in induced sets constitute a factor capable of explaining conflicting reports on the roles of retinal and apparent size in generating FAEs. Perhaps Ss' expectations are relevant too, since frequently the Os in FAE experiments know what the classical findings are, and hence what they might be expected to see. It is not unreasonable to suppose that the presently discussed differences in findings can be explained along such lines. Immergluck himself points out that “... the visual FAE is possibly one of the most volatile and difficult to assess perceptual phenomena.... Instructions, attentional factors, eye movements, sustained fixation, etc., are many of the variables which have to be taken into account when determining the presence, absence, or strength of an FAE [Immergluck, 1968, p. 363]." He uses this point to argue for the need for carefully supervised individual sessions in measuring FAEs. Unfortunately, these are just the conditions under which it is most likely that the E's expectations will influence reports. Without in any way wishing to impugn the experimental abilities of any party to the dispute, I suggest that this possibility be at least considered; to build a strong case against it, one would have to show that Es' expectations (even with naive Os) are ineffective in generating pseudoeffects.

We have found (Gaze \& Dodwell, 1965) that Ss who score high on an index of suggestibility show-as one might expect-a larger amount of set-induced pseudo-FAE than Ss who score low on the same test. The suggestibility test used was Eysenck's body-sway test, so the term "suggestibility" here does not have the connotation of a modality-specific correlation such as that purported to hold between field-dependence and FAEs. In this sense, one may think of suggestibility as perhaps a more fundamental notion than field-dependence (and the strong tendency is to try to explain FAE differences in terms of field-dependence differences, rather than vice versa); one is tempted to think that the reported relations between field-dependence and FAEs may both be related to suggestibility in a complicated way. One comes here to a familiar difficulty with experiments in which the design is essentially correlational: It is not really justifiable to attribute differences in selected groups only to differences on the variable in terms of which they were selected. The application of this point is obvious enough in the present case.

I do not know the field-dependency literature well enough to know whether explanations in terms of (more general) suggestibility can definitely be excluded or not, but I suspect not. In any case, these considerations perhaps suggest that further work in this area should at least take into account the possibility of strongly induced set effects which can be attributed to (probably nondeliberate) behavior on the part of the $\mathrm{E}$.

DODWELL, P. C., \& GENDREAU, L. Figural after-effects, sensory coding, expectation and experience. British Journal of Psychology, in press.

GAZE, L., \& DODWELL, P. C. The role of induced set in figural after-effects. Psychonomic Science, 1965, 2, 275-276.

IMMERGLUCK, L. Visual figural after-effect and field dependence. Psychonomic Science, 1966, 4, 219-220.

IMMERGLUCK, L. Comment on "Figural after-effects, illusions and the dimension of field dependence." Psychonomic Science, 1968, 11, 363.

PRESSEY, A. A reply to comments on "Figural after-effects, illusions and the dimension of field dependence." Psychonomic Science, 1968, 11,364 .

PRESSEY, A., \& KOFFMAN, G. Figural after-effects, illusions and the dimension of field dependence. Psychonomic Science, 1968, 10, 279-280.

STORY, A. Figural aftereffects as a function of the perceived characteristics of the inspection figure. American Journal of Psychology, 1959, 72, 46-56.

WERTHEIMER, M., \& SHEETS, C. A. Effects of instructional set on kinesthetic figural aftereffects. Journal of Experimental Psychology, $77,692-695$

WILLEMS, E. P. Nonstimulus and nonretinal mechanisms in figural aftereffects. Joumal of Experimental Psychology, 1967, 74, 452-454. 